Alcohol Use and Emerging Adult Development:

A Latent Profile Analysis of Community Drinkers

by

Joyce Yueyue Zhu

A thesis submitted in conformity with the requirements

for the degree of Master of Arts

Department of Applied Psychology and Human Development

Ontario Institute for Studies in Education

University of Toronto

(C) Copyright by Joyce Yueyue Zhu 2018 
Alcohol Use and Emerging Adult Development:

A Latent Profile Analysis of Community Drinkers

Joyce Yueyue Zhu

Master of Arts

Department of Applied Psychology and Human Development

University of Toronto

2018

\begin{abstract}
Latent profile analysis was used to establish profiles of emerging adult development and then test associations with drinking behaviors both concurrently and prospectively. To differentiate between different patterns of emerging adult drinking, 153 regular drinkers from the community (ages 18-24 years; $M=20.9, S D=1.9$ ) completed the Inventory of Dimensions of Emerging Adulthood (IDEA) and measures of alcohol use, motives and consequences. The EA-Consistent (90\%) profile had elevated scores on the five typical IDEA subscales; the Non-Exploring EA profile $(10 \%)$ had low scores on four dimensions. The Non-Exploring EA profile consumed significantly less alcohol, experienced fewer alcohol consequences, and had lower social and enhancement motives at baseline and lower scores on drinking volume, alcohol consequences, and social motives at the one-year follow-up. The findings provide support that emerging adult development profiles reflect different patterns of alcohol use and differentiate between those with lower- vs. higher-risk alcohol use.
\end{abstract}




\section{Table of Contents}

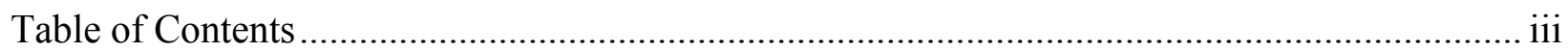

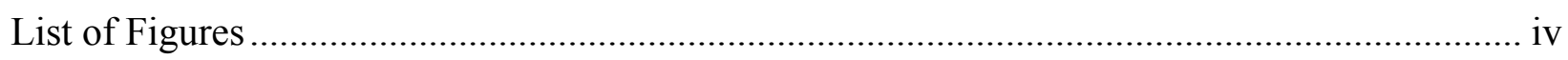

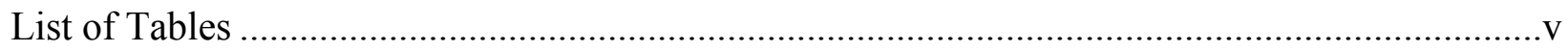

Alcohol Use and Emerging Adult Development: A Latent Profile Analysis of Community

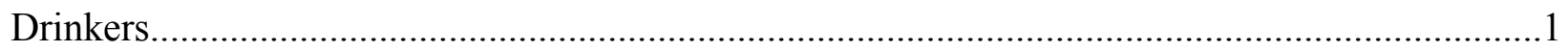

Alcohol Use and Heavy Drinking as a Developmental Phenomenon .............................2

Dimensions of Emerging Adult Development and Alcohol Use ...................................

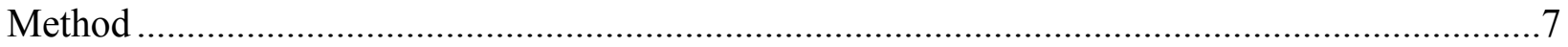

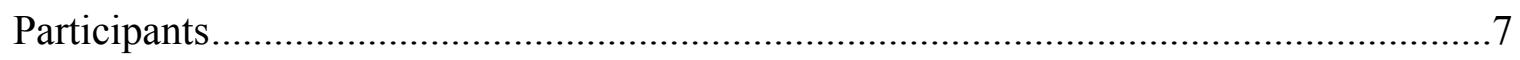

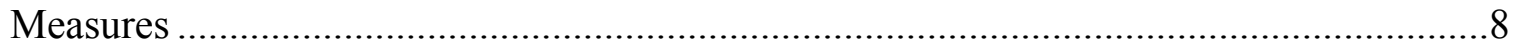

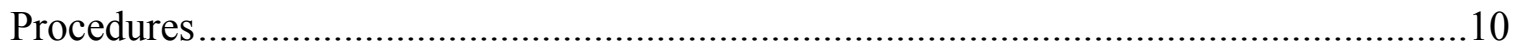

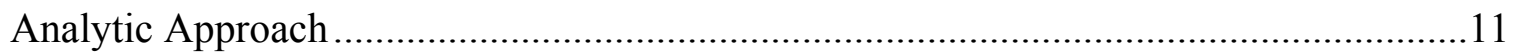

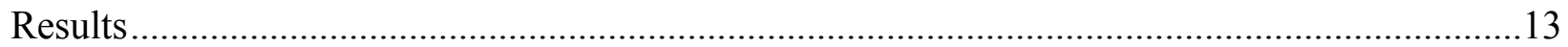

Latent Profile Models ........................................................................................... 13

Profile Differences on IDEA Subscales.................................................................... 14

Profile Differences on Drinking Variables, Psychological Outcomes, and

Demographic and Sociodemographic Variables.....................................................14

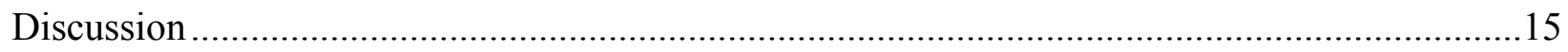

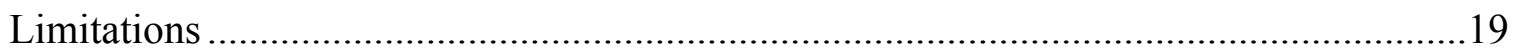

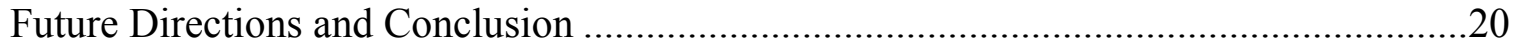

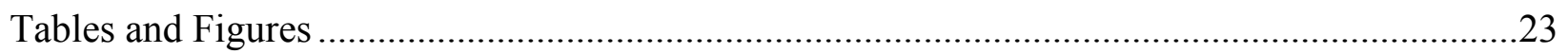

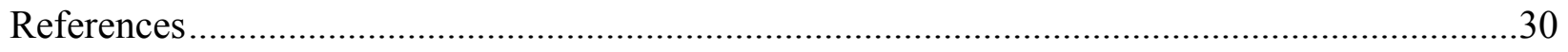




\section{List of Figures}

Figure 1 Estimated means for 2-class latent profile model

Figure 2 Summary of Comparisons among Latent Profiles for Alcohol Outcomes and

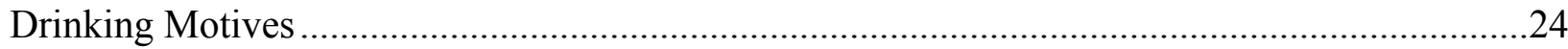




\section{List of Tables}

Table 1 Participants' $(N=153)$ Sociodemographic Variables ...................................................25

Table 2 Summary of Model Fit for Latent Profile Models ......................................................26

Table 3 Means (Standard Errors) for Each Feature of the Inventory of Dimensions of

Emerging Adulthood as a Function of the Profiles and Wald statistic and Cohen's d

Comparing Means and Effect Sizes Across Profiles ..........................................................27

Table 4 Descriptive Statistics for Demographic and Sociodemographic Variables as a

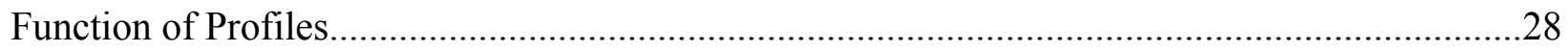

Table 5 Summary of Comparisons among Latent Profiles for Psychological Outcomes.............29 


\section{Alcohol Use and Emerging Adult Development: \\ A Latent Profile Analysis of Community Drinkers}

\section{Emerging Adulthood and Alcohol Use}

Emerging adulthood, the period of development between adolescence and adulthood (Arnett, 2000), has been identified as a time of increased risk for alcohol use and problems (Simons-Morton et al., 2016). Emerging adults in North America engage in the highest levels of past year drinking and binge drinking, relative to other age groups (Boak et al., 2015;

Schulenberg et al., 2017) and experience significant problems associated with their drinking, including increased risk-taking, physical and sexual assault, accidental injury, and legal issues (Kuntsche et al., 2017; Lau-Barraco et al., 2017; Reich et al., 2015). Alcohol problems during emerging adulthood also have long-term negative effects on well-being, educational attainment, employment, and social relationships (Bamberger et al., 2018; Fazzino et al., 2017; Canadian Alcohol and Drug Use Monitoring Survey, 2012).

Although there is a sizeable literature on alcohol use and problems in emerging adulthood, research has largely focused on post-secondary students (Cooper et al., 2016; Schwartz, 2016), who have higher rates of heavy alcohol use relative to their non-college attending peers (Johnston et al., 2016). Nonetheless, several studies on drinking in the years immediately following high school show that, regardless of university attendance, heavy alcohol use and related problems are common among emerging adults in their early twenties (Patrick et al., 2016; Schulenberg et al., 2017). The university environment may contribute to heavy drinking, but does not fully explain the increase in alcohol use and problems in emerging adulthood. Developmental features specific to emerging adulthood, a period marked by transition 
and instability, also contribute to increases in heavy drinking and alcohol problems during this time of life (Arnett, 2005; Sussman \& Arnett, 2014).

\section{Alcohol Use and Heavy Drinking as a Developmental Phenomenon}

Alcohol use and consequences seem to follow a developmental pathway that corresponds with the transitional nature of emerging adulthood. Longitudinal research demonstrates that alcohol use increases throughout adolescence and early adulthood, and then declines from middle emerging adulthood into young adulthood (Johnston et al, 2018; Miech et al., 2017). This is a relatively normative developmental trajectory, with increases in heavy drinking corresponding with the tasks of adolescence and emerging adulthood such as individuation and autonomy, and decreases corresponding with adult role acquisition and increased responsibilities (Bachman et al., 2002; Kendler et al., 2016; Matusiewicz et al., 2016), often referred to as “maturing out” (Jackson \& Sartor, 2016; Jochman \& Fromme, 2010). Because age-related trends are so consistent, some consider heavy drinking a developmental disorder (Sher \& Gotham, 1999; Tarter \& Vanyukov, 1994).

Further support for alcohol use and problems as a developmental phenomenon comes from the drinking motives literature. Drinking motives are generally conceptualized as the final pathway to alcohol use, which mediate distal influences (Cooper et al., 2016; Cooper et al., 1995; Cox \& Klinger, 1988) such as genetics or parenting factors (Van Damme et al., 2015; van der Zwaluw et al., 2011). Motives are associated with different patterns of alcohol use and consequences, beyond the direct effects of alcohol use frequency and quantity (Cooper et al., 2016). For example, individuals who drink for social reasons tend to use alcohol moderately, whereas those who drink to enhance positive affect tend to drink more heavily, and individuals 
who drink to cope with negative affect tend to be more prone to adverse consequences (Kuntsche et al., 2014; Wicki et al., 2017).

Drinking motives correspond with age-related changes in drinking across the lifespan. Patrick and Schulenberg (2011) found that changes in drinking motives covary with binge drinking and by age, with some reasons becoming more prevalent (drinking to relax) and other reasons becoming less prevalent (drinking to get high) as individuals mature. Patrick et al. (2011) found that drinking motives tended to decrease across young adulthood, with the exception of using alcohol to sleep, relax, and because it tastes good, which increased with age. Taken together, these findings suggest that several aspects of drinking follow a particular developmental trajectory, highlighting that heavy drinking and drinking motives are developmental phenomena.

Dimensions of Emerging Adult Development and Alcohol Use

Arnett (2005) presents five psychological dimensions characteristic of emerging adulthood without placing special emphasis on specific accomplishments for successful progression during this developmental transition (Gates et al., 2016). He posits that emerging adulthood is a time of instability characterized by significant physical and psychological transitions. Although not all emerging adults experience difficulties during these transitions (Baggio et al., 2017), the unpredictability of this developmental period can contribute to psychological distress, which may promote alcohol use as a form of coping (Chassin et al., 2009; Mushquash et al., 2013). Emerging adults focus on pursuing their own goals (self-focus), have the opportunity to pursue different paths, and remain optimistic about the future (experimentation or possibilities). A possible consequence of this optimism is the harmful use of alcohol, with minimal regard for its negative consequences. Emerging adults are also not yet 
committed to traditionally-considered adult roles and expectations (feeling in-between), which allows for greater experimentation with substance use. Finally, emerging adulthood typically involves identity exploration; some emerging adults may use alcohol and other substances to alleviate identity confusion or 'try on' different aspects of identity (Arnett, 2005). The Inventory of the Dimensions of Emerging Adulthood (IDEA; Reifman et al., 2007) was developed to measure these five dimensions of emerging adulthood and investigate how they might correspond to various health behaviors, such as alcohol use.

Despite several theoretical discussions of the developmental factors associated with increased alcohol use and consequences in emerging adulthood, only a handful of previous studies have empirically examined the relationships between Arnett's theory of emerging adult development and alcohol use. Davis et al. (2018) conducted a meta-analysis of the relationship between substance use and emerging adult development using the IDEA. They found that several IDEA subscales (identity exploration, experimentation, negativity/instability, feeling in-between) were associated with alcohol use, with smaller effects for other substance use (total studies $=$ 168 ; absolute effect $=.15$ ). The authors attributed these findings to the unique developmental relationship between alcohol use and markers of emerging adulthood, but called for further longitudinal examination to better elucidate these relationships. Gates et al. (2016) found that several facets of the IDEA (experimentation/possibilities, negativity/instability) predicted failure to mature out of heavy drinking and alcohol-related problems, but only in the context of the transition out of college. In a correlational study, Smith et al. (2014) found that only feeling-inbetween was associated with substance-related consequences, including alcohol problems. Lisha et al. (2014) found that experimentation/possibilities was associated with past 30-day alcohol use, but they did not test for all of Arnett's features of emerging adulthood. Finally, Allem et al. 
(2016) found that those who rated their emerging adult experience as a time of focusing on others were less likely to report binge drinking but these findings were limited to a sample of Hispanic emerging adults. As noted above, the previous research is limited in several ways, including the lack of research on non-college samples, a restricted focus on alcohol use and problems without considering motives for drinking, and the use of cross-sectional designs assessing the features of emerging adulthood and alcohol use at a single time-point. The current study addresses several of these limitations by using a more diverse sample consisting of both university and non-university attending emerging adults, including motives for drinking due to their critical role as proximal predictors of alcohol use and consequences, and the inclusion of a second time-point for a more robust analysis of the relationship between the features of emerging adulthood and alcohol use, consequences, and motives.

Because the transition from adolescence to adulthood is not a homogeneous process (Chen et al., 2012; Cleveland et al., 2013), the relationship between emerging adult development features and alcohol use and problems may be best examined using a person-oriented approach. Latent profile analysis (LPA) classifies individuals into distinct profiles based on IDEA scores and compared on various alcohol indices, providing a better understanding of the heterogeneity of emerging adulthood and variations in drinking behaviors. Recently, Lanctot and Poulin (2018) examined relations between IDEA latent profiles and several outcome variables and found several distinct profiles that differentially corresponded with psychological outcomes and alcohol problems. However, they did not account for rate of classification uncertainty. Because classifications are based on probabilistic information of class-membership probabilities, failure to account for rate of classification uncertainty can lead to misclassified individuals and inaccurate estimations of the relationship between profiles and outcomes of interest. Standard 
errors for parameter estimates are likely underestimated (Clark \& Muthen, 2009; Loken, 2004), which can lead to biased estimates of the relations between the latent classes and auxiliary variables and model parameters (Clogg, 1995; Hagenaars, 1993). In addition, Lanctot and Poulin (2018) had a broad focus that only included alcohol problems and not other important alcohol use variables, including drinking frequency, volume, binge-drinking, and motives. Finally, they did not examine whether relations between IDEA latent profiles and alcohol outcomes persisted over time.

It is important to note that not all emerging adults drink hazardously or experience alcohol consequences. Alcohol use during emerging adulthood can serve important constructive functions, such as friendship formation and personal identity exploration (Arnett, 2005; White \& Jackson, 2004). Indeed, when considering drinking motives among emerging adults, social motives are the most frequently endorsed, whereas other drinking motives (i.e., coping, conformity, and enhancement) are less prevalent and tend to relate to more problematic alcohol use (Kuntsche et al., 2014; Wicki et al., 2017). Therefore, it is important to differentiate between those who participate in normative emerging adult drinking from those who engage in more harmful drinking practices. Data from Monitoring the Future (MTF) shows that 32 percent of college students engage in binge-drinking, yet only 3.1\% drink daily (Johnston et al., 2016), indicating that while some participate in frequent alcohol use resulting in outcomes such as ischaemic heart disease, others may engage in heavy episodic binge drinking resulting in other adverse outcomes such as alcohol-related injury (Bagnardi et al., 2008; Gmel et al., 2006; Gmel et al., 2011). Such differences in drinking patterns may correspond to variability in experiences of emerging adulthood, where 'normative' patterns of drinking (e.g. binge) reflect a more typical emerging adult experience. 
Finally, few studies have examined whether the relationship between emerging adulthood characteristics and drinking outcomes persist over time. For example, Gates et al. (2016) found effects of Arnett's emerging adult identity dimensions on alcohol problems over time but they were small in magnitude. Additional longitudinal research is needed to draw firmer conclusions about the relationship between emerging adult development and alcohol use across time.

The purpose of the current study was to use a person-centered LPA approach to understand how heterogeneous profiles reflecting unique patterns of emerging adult development are associated with variations in drinking behaviors, consequences, and motives. In addition, we assessed whether the relationship between features of emerging adulthood and drinking outcomes persist after one year. Based on previous research on the relationship between Arnett's dimensions of emerging adult identity and alcohol use (Gates et al., 2016; Lisha et al., 2014; Smith et al., 2014) we anticipated that emerging adult profiles reflecting greater identity exploration, experimentation/possibilities, self-focus, feeling in-between, and negativity/instability will be associated with higher levels of binge drinking, alcohol problems, and social drinking motives, which are typical of emerging adulthood. Because background variables are related to perceptions of emerging adulthood (Reifman et al., 2007; Tagliabue et al., 2016), we also examined sociodemographic variables in relation to features of emerging adulthood.

\section{METHOD}

\section{Participants}

Participants were 153 current drinking emerging adults (ages 18-24 years; $M=20.9, S D$ $=1.9$ ) who completed a baseline and one year follow-up survey as part of a larger study on alcohol use and problems in EA (Goldstein et al., 2018). Participants were eligible if they had 
consumed alcohol on at least two occasions in the last 30 days and were fluent in written English. Participants were predominantly female (66.0\%), Caucasian (50.3\%), university or college students $(68.0 \%)$, and in a romantic relationship $(52.9 \%)$. Table 1 reports sample sociodemographic characteristics.

\section{Measures}

All measures were administered at baseline and again at one-year follow up.

Demographics. Demographic and sociodemographic information included participants' sex, age, ethnicity, relationship status, education (current, past), family income, employment status, and living status.

Dimensions of emerging adult development. Emerging adulthood development was measured using the Inventory of the Dimensions of Emerging Adulthood (IDEA) a 31-item measure of five dimensions (Reifman et al., 2007): The 5-item experimentation/possibilities subscale ("A time of trying out new things"; $\alpha=.79$ present sample baseline), the 6 -item selffocus subscale ("A time of personal freedom"; $\alpha=.72$ present sample baseline), the 7-item negativity/instability subscale ("A time of feeling stressed out”; $\alpha=.81$ present sample baseline), the 7-item identity exploration subscale ("A time of finding out who you are"; $\alpha=.82$ present sample baseline), the 3-item feeling in-between subscale ("A time of feeling adult in some ways but not others"; $\alpha=.75$ present sample baseline), and the 3 -item other-focused subscale ("A time of responsibility for others"; $\alpha=.61$ present sample baseline) which serves as a counterpoint to self-focus. Responses are scored on a 4-point scale ranging from 1 (strongly disagree) to 4 (strongly agree). The IDEA was found to have good internal consistency (Cronbach's alpha ranging from .70 to .85), test-retest reliability, and factorial validity in young adults (Reifman et al., 2007). 
Alcohol Use. Alcohol use was assessed with a 30-day Timeline Follow-back questionnaire (TLFB; Sobell \& Sobell, 1992), which was administered as an interview by a research assistant (frequency $=$ number of days drinking over 30 days; binge drinking $=$ number of days binge drinking over 30 days, volume $=$ number of drinks consumed over 30 days; quantity $=$ average drinks per drinking day). Participants were provided with a calendar of the past 30 days and instructed to first indicate holidays and/or special celebrations to use as memory anchors. For each calendar day, participants were then asked to indicate how many drinks they consumed. ${ }^{1}$

Alcohol Consequences. Past year alcohol consequences (yes/no) were measured with the 24-item Brief Young Adult Alcohol Consequences Questionnaires (B-YAACQ; "I have passed out from drinking”). The B-YAACQ has good internal consistency $(\alpha=.83)$ as well as good test-retest reliability, and concurrent validity in young adults (Kahler et al., 2005; Kahler et al., 2008). Internal consistency in the present sample was good (baseline: $\alpha=.87$; follow-up: $\alpha=$ $.89)$

Drinking Motives. Alcohol use motives were assessed with the 20-item Drinking Motives Questionnaire Revised (DMQ-R; Cooper, 1994), which consists of four 5-item subscales: Coping ( $\alpha=.88$; "To forget your worries"; $\alpha=.85$ present sample baseline, $\alpha=.82$ follow-up), Social ( $\alpha=.82$; "To celebrate special occasions with friends"; $\alpha=.83$ present sample baseline, $\alpha$ $=.90$ follow-up), Enhancement ( $\alpha=.85$; "Because it's fun"; $\alpha=.85$ present sample baseline, $\alpha$ $=.88$ follow-up), and Conformity ( $\alpha=.87$; "Because your friends pressure you to drink"; $\alpha=$ .86 present sample baseline, $\alpha=.79$ follow-up). Participants indicate how frequently [1 (Almost

\footnotetext{
${ }^{1}$ A standard drink was defined as one bottle of beer (12oz, 5\%), one glass of wine (5oz, $\left.10 \%-12 \%\right)$, or one shot of hard liquor (1.5oz, 43\%-50\%; Collins et al., 2008).
} 
Never/Never) to 5 (Almost Always/Always)] they drink alcohol for each reason listed. Responses are averaged for each subscale. The DMQ-R has good internal consistency, predictive validity, convergent validity, and factorial validity (Cooper, 1994; Kuntsche et al., 2006).

Depression. The Centre for Epidemiological Studies Depression Scale (CES-D; Radloff, 1977 ) is a 20 -item questionnaire used to assess depression across a range of symptoms ( $\alpha=.85$; "I felt sad"). Response options range from 0 (Rarely or None of the Time) to 3 (Most or Almost All the Time). The CES-D has good internal consistency, concurrent validity, and construct validity in the general population (Radloff, 1977). There was good internal consistency in present sample (baseline: $\alpha=.91$; follow-up: $\alpha=.91$ )

Anxiety. The Generalized Anxiety Disorder 7-item scale (GAD-7; Spitzer et al., 2006) was used to assess generalized anxiety disorder across a range of symptoms ( $\alpha=.89$; "Worrying too much about different things." Responses are scored on a 4-point scale $(0=$ Not at all sure, 1 $=$ Several days, $2=$ Over half the days, $3=$ Nearly every day). The scale has good internal consistency, construct validity and factorial validity in the general population (Löwe et al., 2008). There was good internal consistency in the present sample (baseline: $\alpha=.89$; follow-up: $\alpha=.92)$.

\section{Procedures}

Participants were recruited through online classified advertisements (Craigslist, Kijiji), social media (Twitter and Facebook), newspaper advertisements, and fliers posted around a university campus located in a major Canadian city. Interested participants contacted the lab, were screened for study eligibility and then invited to attend the baseline session within one week of the screening. Participants were asked to bring photo ID to verify their age. Participants signed a consent form and were given computer access to complete the online baseline survey in 
the lab. Participants were paid \$25 for the initial assessment and \$25 at the follow-up visit 1 year later. All study procedures were approved by the Research Ethics Board.

\section{Analytic Approach}

LPA was conducted using the six IDEA subscales: identity exploration, experimentation/possibilities, negativity/instability, other-focused, self-focused, feeling-inbetween. LPA is a type of latent variable mixture model where the latent variable is derived by assigning individuals to a profile (or class) based on responses to the indicator variables (e.g., IDEA subscores). LPA identifies classes of individuals that are similar on observed continuous indicators. All analyses were conducted using Mplus Version 8 (Muthén \& Muthén, 1998-2017), using the automatic three-step approach to model auxiliary variables (i.e., antecedents, outcomes; Asparouhov \& Muthén, 2013). The superiority of the Mplus 3-step LPA approach has been demonstrated in simulation studies (Asparouhov \& Muthen, 2013) and has the advantage of accounting for measurement error in profile classification by using estimated posterior class probabilities and number of individuals assigned to each latent class to compute classification uncertainty rates, providing greater accuracy in determining associations between the profile and external variables (Asparouhov \& Muthen, 2013; Kamata et al., 2018; Wang \& Hanges, 2011).

In the first step, the LPA is conducted to determine the number of classes that fit the data. This is accomplished by identifying each individual's likelihood, or posterior probability of being in each class. Second, the most likely class membership (or the profile to which an individual most likely belongs) is calculated based on the posterior distribution from the previous step (Asparouhov \& Muthen, 2013), and individuals are assigned to the class in which their posterior probability is highest, taking into account the rate of classification uncertainty. Several models are estimated indicating different numbers of classes and the optimal number is determined using 
model comparison criteria. The Akaike Information Criteria (AIC) and sample size-adjusted Bayesian Information Criteria (BIC) were used to assess model fit, with lower values indicating better model fit (Nylund et al., 2007). Additionally, the Lo-Mendell-Rubin (LMR) likelihood ratio test assesses if the current number of classes $(\mathrm{k})$ is a better fitting model than a model with one fewer class ( $\mathrm{k}-1$; Wang $\&$ Wang, 2012). In addition, models were compared on entropy (Muthen, 2004), with values closer to 1.0 indicating better classification quality. These criteria together were used to determine the best-fitting model along with the theoretical meaning of the solutions.

Finally, the most likely class membership is used to examine class differences on external correlates not included in the latent model, taking into account the classification error rate. These external correlates include participants' drinking behaviors and motives at time 1 (baseline) and time 2 (one year later), as well as psychological outcomes (anxiety, depression), and demographic (age, gender) and sociodemographic variables (living with parents, employed). Finally, class comparisons of the IDEA subscale scores were examined using Wald's test. All external correlates were specified as continuous distal outcomes (drinking variables, psychological outcomes, and demographic variables) with unequal means and variances in each class, except for the sociodemographic variables (in a romantic relationship, living with parents, employed, in school), which were specified as categorical outcomes.

Because symptoms of anxiety and depression are prevalent in emerging adulthood (Kessler \& Wang, 2008) and thought to correspond with the developmental and transitional stressors characteristic of this time of life (Arnett et al., 2014; Bishop et al., 2018; Taylor et al., 2014), it was also necessary to examine the possibility that psychopathology (i.e., anxiety and 
depression symptoms), rather than developmental differences, contributed to drinking differences between emerging adult profiles.

\section{RESULTS}

\section{Latent Profile Models}

Models with a 1-, 2-, 3-, 4- and 5-class solution were examined. Fit statistics for the five LPA models are presented in Table 2. The AIC and BIC consistently decreased as additional classes were added. The best log-likelihood value was not replicated for the 4- and 5-class models, the latter of which also did not converge. This suggests that parameter estimates may be unreliable, local maxima were reached, and/or that the model attempted to extract too many classes (McLachlan \& Peel, 2000). Thus, the 4- and 5-class models were rejected. The 2- and 3class models converged, and the best log-likelihood value was replicated (Table 2). Both the 2and 3-class models yielded significant p-values for bootstrap likelihood ratio test (BLRT).

Compared to the 2-class model, the 3-class model yielded a lower sample size-adjusted Bayesian information criterion (BIC). The p-value for LMR-LRT, however, was not significant for both the 2- and 3-class model.

Entropy values were high for both the 2- and 3-class models, but the 2-class model had an entropy value of .930 , slightly higher than the other models, which indicates a superior level of classification accuracy. Additionally, the relative size of each latent class should not be too small, and should not contain fewer than 5\% of participants (Wang \& Wang, 2012) - a criterion which the 3-class solution did not satisfy. Results for the 2-class solution indicate that both profiles contained more than $5 \%$ of participants, one closer to $10 \%$, the other $90 \%$. Further, based on visual inspection, 2 of the 3 classes in the 3-class model shared conceptually similar trends on the IDEA facets, with high elevations on all dimensions except other-focused, 
consistent with typical emerging adult development. In contrast, the 2-class model included two classes with distinct trends on most of the IDEA facets, one class showing high elevations on all dimensions except other-focused, another showing lower scores on all dimensions, particularly identity exploration and feeling in-between, which is somewhat atypical of emerging adult development. After considering all criteria, the 2-class solution was determined most optimal. Profile 1 was labeled Non-Exploring EA and Profile 2 was labeled EA-Consistent (Figure 1). Profile Differences on IDEA Subscales

Profile comparisons indicated significant differences on the subscales identity exploration, experimentation/possibilities, self-focused, and feeling-in-between (Table 3). The two profiles were best differentiated on identity exploration (Cohen's $d=3.191$ ) and feeling-inbetween (Cohen's $d=2.562$ ). Differences in negativity/ instability scores were not statistically significant using chi-square statistic.

Profile Differences on Drinking Variables, Psychological Outcomes, and Demographic and Socio-demographic Variables

There were no profile differences on demographic or sociodemographic variables (Table $4) .^{2}$

Results indicate profile differences on drinking variables (Figure 2). At baseline, there were significant profile differences in alcohol outcomes across 30 days: frequency (number of days drinking), binge drinking (number of days binge drinking), volume (number of drinks), and quantity (average drinks per drinking day). There were also significant differences in drinking consequences. At follow-up, there remained significant differences in drinking volume and

2 Ethnicity categories were merged to create a binary variable for profile comparisons due to the small size of one of the classes. 
drinking consequences. There were no significant differences in number of days drinking (follow-up), number of days binge drinking (follow-up) and average drinks per drinking day (follow-up). Finally, there were profile differences in drinking motives for social (baseline and follow-up) and enhancement motives (baseline) but not for coping or conformity motives at either timepoint. For all drinking variables, Profile 1 ("Non-Exploring EA") demonstrated significantly lower scores than Profile 2 (“EA-Consistent"). ${ }^{3}$ There were no differences on psychological outcomes (anxiety and depression) (Table 5).

\section{DISCUSSION}

The goals of this study were to examine the relationship between emerging adult development profiles and a wide range of drinking outcomes and to test whether the relations persisted across time. Because alcohol use is often perceived as normative in emerging adulthood (Arnett, 2005; Davis et al., 2018), our sample consisted of regular drinkers, which enabled us to differentiate between emerging adults who engage in drinking that results in consequences from those whose drinking reflects less harmful patterns.

Despite common experiences that serve as markers for this time of life (Arnett, 2000), emerging adults are a heterogeneous group who vary in the degree to which they identify with psychological changes considered characteristic of emerging adulthood. The EA-Consistent profile maps onto the features that are typical of emerging adulthood, with elevated scores on all five normative features of emerging adulthood. The Non-Exploring EA is comparatively atypical. This profile reflects individuals who perceive themselves as more stable in their identity and status and have significantly lower scores than the EA-Consistent profile on four of the five

${ }^{3}$ See Supplemental Materials for Table of Correlations of All Study Variables, including IDEA subscales and drinking variables. 
normative features of emerging adulthood. Furthermore, the two profiles were most distinguished by differences in the identity exploration and feeling in-between subscales of the IDEA, consistent with other theories regarding variability in the identity formation process that begins in adolescence and becomes increasingly salient in emerging adulthood (Erickson, 1968; Marcia, 1996).

Our findings are also consistent with previous theoretical and empirical research on emerging adult development and alcohol use (Arnett, 2005; Davis et al., 2018; Gates et al., 2016; Smith et al., 2014; Sussman \& Arnett, 2014). As predicted, members of the profile with higher levels of identity exploration, experimentation/possibilities, self-focus, and feeling in-between, used more alcohol in terms of quantity (average drinks per drinking day), frequency (number of days drinking over 30 days) volume (number of drinks consumed over 30 days), binge drinking (number of days binge drinking over 30 days), and experienced greater alcohol-related problems. This finding supports the theoretical literature suggesting that elevations on these characteristics of emerging adulthood increase susceptibility to alcohol use (Arnett, 2005; Sussman \& Arnett, 2014). Constructing a stable identity and a feeling of being in-between adolescent and adult role expectations can be confusing and challenging. As a result, some emerging adults may use alcohol in an effort to alleviate identity confusion or embrace the increased personal freedom associated with this time of life to experiment or "try on" different behaviors and activities, particularly those associated with adulthood, such as alcohol use. This finding is also consistent with previous empirical studies that have found evidence of associations between alcohol consumption and emerging adult development using the IDEA scale (Davis et al., 2018; Smith et al., 2014), especially identity development (Bishop et al., 2005; Hagger-Johnson et al., 2013). Our discovery of the Non-Exploring EA profile is particularly interesting. Not only is 
this profile somewhat atypical of emerging adult development according to Arnett's theory, it is also consistently lower on all alcohol-use variables compared to the EA-Consistent profile. This pattern suggests that the Non-Exploring EA profile represents a small group of regular drinkers that do not embody the typical psychological changes of emerging adulthood and consume significantly less alcohol in terms of volume, frequency, quantity, binge-drinking, and experience fewer alcohol problems. As a result, this Non-Exploring EA profile appears to represent a subtype of emerging adults who are low-risk drinkers.

Since this group did not differ from the EA-Consistent group on any demographic and socio-demographic variables including age, employment status, education status (in or out of school), and living status (independently or with parents), it is unlikely that this pattern of lowrisk drinking can be attributed to "maturing out" (Jochman \& Fromme, 2010), which is believed to occur between middle emerging adulthood and young adulthood (Johnston et al., 2018; Miech et al., 2017) and known to coincide with adult role acquisition (Bachman et al., 2002; Kendler et al., 2016; Matusiewicz et al., 2016). However, because we did not assess whether participants perceived themselves as adults or had achieved typical adult milestones such as financial independence or parenthood, we are not able to rule out the possibility that members of this group have already successfully transitioned into adulthood. It is also possible that members of the Non-Exploring EA group have not yet progressed into the emerging adult period despite their age (Goodman et al., 2015), and are not yet participating in the pattern of riskier drinking that is common during this time of life (Patrick et al, 2016; Schulenberg et al., 2017).

Our descriptions of profiles are similar to past research examining subgroups of emerging adults. Lanctot and Poulin (2018) found a profile characterized by low scores for all emerging adulthood features, which represented the smallest subgroup compared to other identified 
profiles. Similar to our Non-Exploring EA profile, members of this profile engaged in lower levels of problematic alcohol use. They also found a profile similar to our EA-Consistent profile characterized by high scores on all dimensions of emerging adulthood and endorsing higher levels of problematic alcohol use.

Our study was the first to examine drinking motives with IDEA latent profiles. Consistent with our predictions, members of the EA-Consistent profile experienced greater social drinking motives. This finding fits with the understanding that alcohol use in emerging adulthood can serve important constructive functions, such as friendship formation and personal identity exploration (Arnett, 2005; White \& Jackson, 2004), and that drinking for social situations are the most frequently endorsed (see van Damme et al., 2013; Wicki et al., 2017). We also found that members of the EA-Consistent profile not only drank more alcohol than those of the NonExploring EA profile, but also drank more for enhancement reasons (i.e., to have fun), consistent with the literature indicating that those who drink to enhance their mood tend to use alcohol more heavily (Cooper et al., 2016; Kuntsche et al., 2014). This pattern also suggests that members of EA-Consistent profile drank more than those of the Non-Exploring profile for positive reinforcement reasons while showing no differences on negative reinforcement reasons. Higher enhancement and social motives within the EA-Consistent profile are consistent with findings that elevations in these motives commonly co-occur particularly in emerging adult binge-drinkers (Kuntsche et al., 2010).

Our findings indicate that the relationship between emerging adult development profiles and drinking outcomes (volume, consequences, and social motives) persisted across time. Our study is one of the few to use a person-centered approach to examine this relationship longitudinally. Lisha et al. (2015) used latent growth curve modeling and found that those who 
were experiencing reductions in emerging adult identity features on the IDEA had greater frequency of drinking than those experiencing steep increases. Although this result is surprising given the expectation that drinking behaviors increase upon entering emerging adulthood, this study used the shortened version of the IDEA scale and involved at-risk continuation high school students, which may have restricted assessment of the relationship between emerging adult identity formation and alcohol use more generally and across time. Gates et al. (2016) found effects of Arnett's emerging adult identity dimensions on alcohol problems over time in the transition out of college, but they were small in magnitude and a person-centered approach was not implemented. Our findings provide support that emerging adult development profiles not only relate to certain drinking behaviors, motives, and consequences, but can predict those drinking outcomes after one year in a community context that is not based on a university environment alone.

\section{Limitations}

Despite the novelty of these findings, there are several limitations of this study that should be noted. First, the sample size of the individual latent classes were imbalanced, with one class significantly bigger than the other $(15 / 153,138 / 153)$. The unequal grouping of class membership presents issues of power for detecting effects with certainty. Nonetheless, the NonExploring EA profile consistently demonstrated less alcohol consumption in frequency, binge drinking, volume, and quantity at Time 1 with some effects persisting a year later, suggesting a robust finding with effects in the same direction. Second, there are limitations to the generalizability of our findings. While the person-centered approach of latent profile analysis is valuable, it can be idiosyncratic to the specific sample tested and does not always generalize well to different samples. 
Furthermore, the two profiles identified here may also reflect different personality styles that contribute to alcohol use. For example, higher emerging adult experimentation may reflect increased sensation seeking and impulsivity, which are both strong personality correlates of alcohol involvement (Quinn \& Harden, 2012; Thompson et al., 2015). Thus, individuals high on sensation-seeking and impulsivity might be motivated to engage in novel and stimulating experiences like alcohol use, and more likely to score higher on experimentation/possibilities. Future research should examine and control for the influence of sensation-seeking and impulsivity on emerging adult identity status. Finally, while there were no significant differences across profiles in sex, status of romantic relationships, employment, school, or living situation to suggest that profile differences are related to sociodemographic variables, it is nonetheless possible that transitions (e.g., living with their parents or entering a relationship in the last year) might have a greater impact on self-perceptions of emerging adulthood identity than current status. Since our study assessed for current status but not transitions, it was not able to assess the possible role of socio-demographic transitions on self-identification with features of emerging adulthood and drinking outcomes.

\section{Future Directions and Conclusion}

The pattern of low scores on IDEA subscales in the Non-Exploring EA profile, particularly on identity exploration and feeling in-between, may serve as a "marker" to identify and predict low-risk drinkers in other samples as well as to better understand the factors that confer resilience or protect these drinkers from harmful drinking and related consequences. Although drinking culture is prevalent in emerging adulthood, with alcohol experimentation considered normative during this period (Arnett, 2005), the existence of a Non-Exploring EA profile reinforces the notion that not all emerging adults who drink alcohol regularly experience 
harmful consequences. A next step for this research is to identify additional factors grounded within the developmental context that may contribute to this group's safer drinking profile. Empirical and theoretic research suggests that social support strongly predicts positive emerging adult adjustment (Galambos, 2006; Lane, 2014). Thus, healthy and strong social relationships with peers or family during this time period may be protective against risky drinking. Given the prevalence of drinking behavior and adverse drinking consequences among emerging adults, identifying factors that protect regular drinkers from risky alcohol consumption is a practical strengths-based approach that avoids reliance on abstinence as the only option.

Our findings suggest that the psychological experience of identity exploration and feeling in-between seems especially important in distinguishing between drinking behavior and consequences in emerging adults. Since the emerging adult development profiles were found to predict drinking outcomes across time, there are implications for clinical interventions. A major challenge associated with the transition to adulthood is the exploration of one's identity, which can involve a process of questioning previously held beliefs and actively exploring alternative philosophies (Arnett, 2005; Erikson, 1968; Phinney and Kohatsu, 1997). This process often occurs in the realm of work and romantic relationships (Arnett, 2005), and can involve changes in self-definition as well as the formation of new identities. As constructing a stable identity can be confusing and difficult, alcohol use may help to alleviate some of the stress associated with those difficulties (Annett, 2005; Sussman \& Arnett, 2014). Another challenge of emerging adulthood is feeling caught between adolescence and adulthood and struggling to achieve or commit to traditionally-considered adult roles and expectations (Arnett, 2005), which can lead to greater experimentation with substances such as alcohol than those who feel they have reached adulthood. Therefore, interventions should target psychological adjustment issues associated 
with emerging adult identity exploration and feeling-in-between through psychological counselling or peer support. Psychological support may help emerging adults cope with these challenges in a more adaptive way and minimize problematic drinking behavior. Future alcohol interventions among emerging adults should not exclusively target emotion dysregulation or pathology, but pay greater attention to addressing the challenges and distress associated with the unique psychological experience of feeling caught between the expectations of two developmental stages, and exploring one's identity during emerging adulthood. 


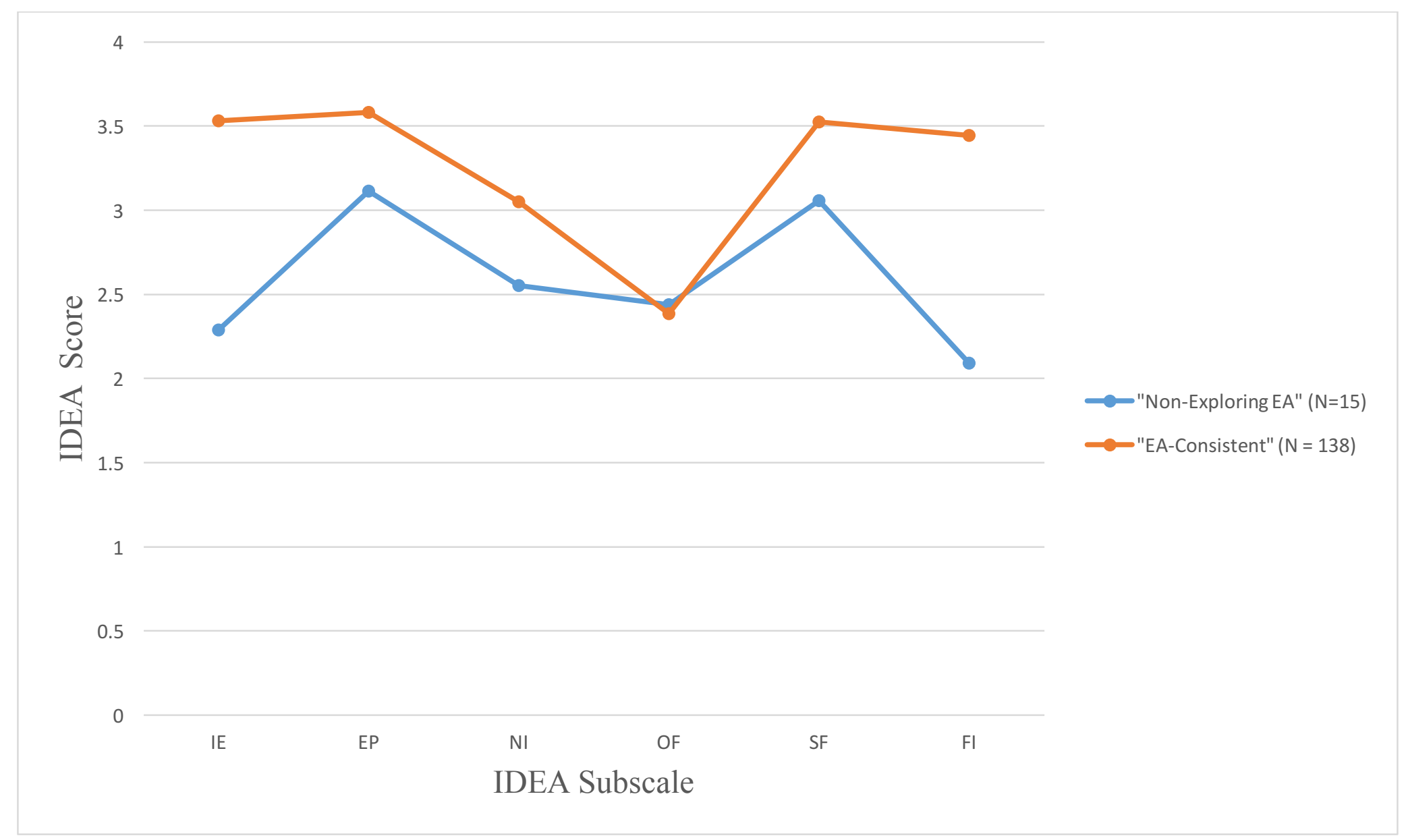

Figure 1.

Estimated means for 2-class latent profile model. IE = Identity Exploration; EP = Experimentation/ Possibilities; NI = Negativity/Instability; OF = Other-Focused; SF = Self-Focused; FI = Feeling In-Between. 

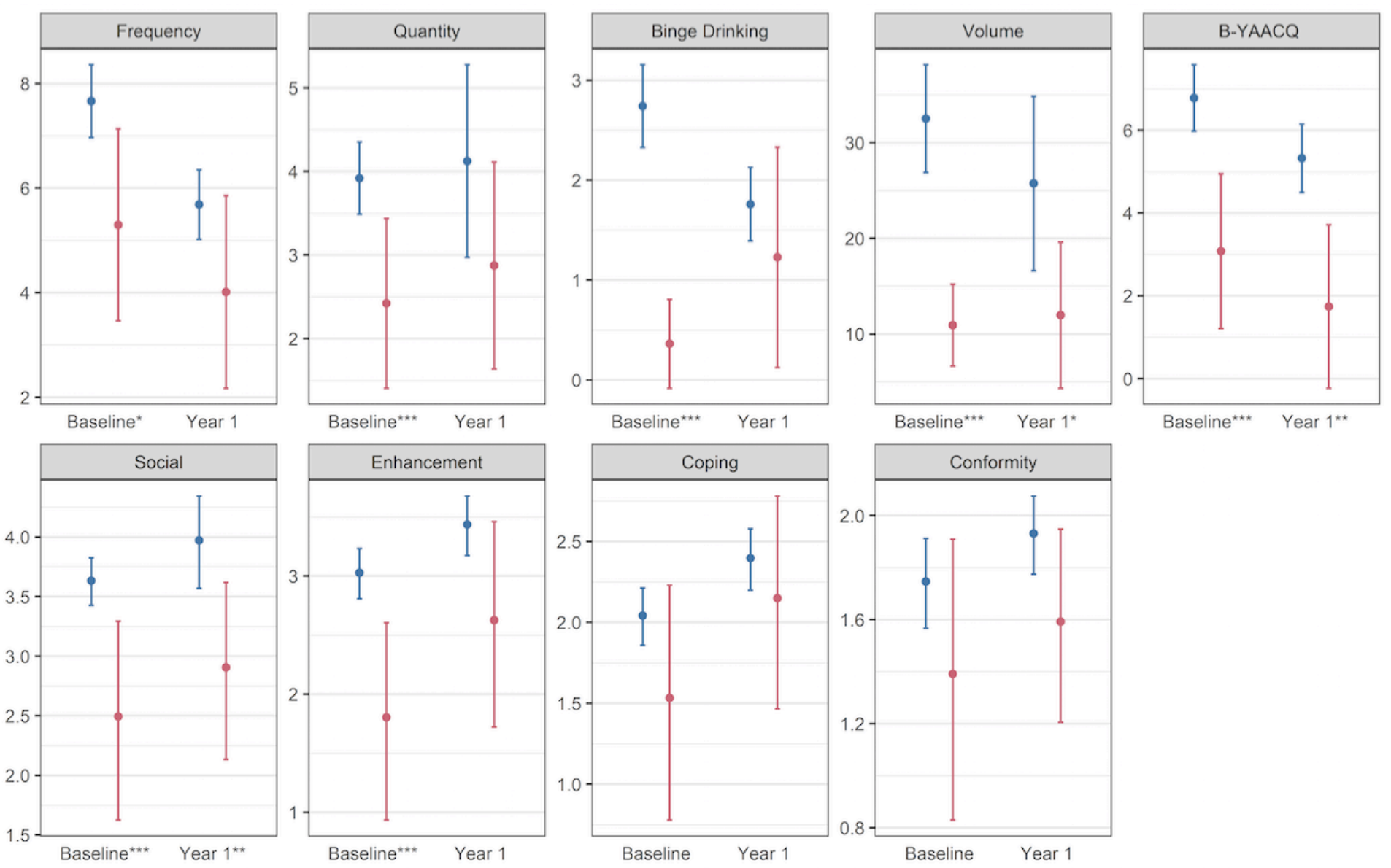

$\rightarrow$ EA-Consistent

$\rightarrow$ Non-Exploring

\section{Figure 2.}

Summary of Comparisons among Latent Profiles for Alcohol Outcomes and Drinking Motives. ${ }^{*} p<.05 ; * * p<.01 ; * * *<.001$.

Frequency $=$ number of days drinking over 30 days. Binge drinking $=$ number of days binge drinking over 30 days. Volume $=$ number or drinks consumed over 30 days. Quantity = average drinks per drinking day. BYAACQ = alcohol problems. Social $=$ social motives. Enhancement $=$ enhancement motives. Coping $=$ coping motives. Conformity $=$ conformity motives. 
Table 1. Participants' $(N=153)$ Sociodemographic Variables

\begin{tabular}{|c|c|c|c|}
\hline \multicolumn{2}{|l|}{$\begin{array}{l}\text { Sociodemographic } \\
\text { Variable }\end{array}$} & \multicolumn{2}{|l|}{$\begin{array}{l}\text { Mean (SD)/ } \\
\text { Percentage }\end{array}$} \\
\hline Average Age & & $20.96(1.91)$ & - \\
\hline \multirow[t]{3}{*}{ Gender } & Female & $66.0 \%$ & 101 \\
\hline & Male & $33.3 \%$ & 51 \\
\hline & Other & $.7 \%$ & 1 \\
\hline Ethnicity & Caucasian & $50.3 \%$ & 77 \\
\hline \multicolumn{3}{|l|}{ Relationship } & 81 \\
\hline $\begin{array}{l}\text { Living in parents' } \\
\text { home }\end{array}$ & Yes & $35.3 \%$ & 54 \\
\hline Employment Status & Employed & $54.2 \%$ & 83 \\
\hline In School (\%) & Yes & $68.0 \%$ & 104 \\
\hline Educational & "Some high school (grade 9 to grade 12)" & $.7 \%$ & 1 \\
\hline \multirow[t]{5}{*}{ Attainment ${ }^{\mathrm{a}}$} & "Graduated high school (completed grade 12)" & $6.5 \%$ & 10 \\
\hline & "Some community college or some university" & $56.9 \%$ & 87 \\
\hline & "Graduated community college or university" & $24.2 \%$ & 37 \\
\hline & "Some graduate school (post university)" & $8.5 \%$ & 13 \\
\hline & "Graduate degree (Master's, Ph.D., MD)" & $2.0 \%$ & 3 \\
\hline \multirow[t]{6}{*}{ Family Income } & $1=$ "Less than $\$ 20,000 "$ & $15.7 \%$ & 24 \\
\hline & $2=“ \$ 20,000-\$ 40,000 ”$ & $11.1 \%$ & 17 \\
\hline & $3=“ 40,000-\$ 60,000 "$ & $15.7 \%$ & 24 \\
\hline & $4=" \$ 60,000-\$ 80,000 "$ & $19 \%$ & 29 \\
\hline & $5=" \$ 80,000-\$ 100,000 "$ & $13.7 \%$ & 21 \\
\hline & $6=" \$ 100,000+$ & $24.2 \%$ & 37 \\
\hline
\end{tabular}

${ }^{a}$ Note. Two participants had missing information on educational attainment.

${ }^{b}$ Note. One participant had missing information on family income 
Table 2. Summary of Model Fit for Latent Profile Models

\begin{tabular}{|c|c|c|c|c|c|c|c|}
\hline Profiles & $\begin{array}{l}\text { Log } \\
\text { Likelihood }\end{array}$ & AIC & $\mathrm{BIC}$ & Entropy & LMR-LRT $(p)$ & $\operatorname{BLRT}(p)$ & $\begin{array}{l}\text { Proportion of } \\
\text { smallest } \\
\text { group }\end{array}$ \\
\hline 1 & -770.333 & 1564.667 & 1563.051 & - & - & - & - \\
\hline 2 & -770.333 & 1461.393 & 1458.835 & .930 & .270 & $<.0001$ & $15 / 153$ \\
\hline 3 & -711.697 & 1398.548 & 1395.048 & .886 & .286 & $<.0001$ & $7 / 153$ \\
\hline $4^{i}$ & -673.274 & 1342.395 & 1337.952 & .895 & .052 & $<.0001$ & $1 / 153$ \\
\hline $5^{\mathrm{i}}$ & -622.678 & 1325.356 & 1319.971 & .869 & .575 & .0300 & $1 / 153$ \\
\hline
\end{tabular}

Note. AIC; Akaike information criterion. BIC; sample-size adjusted BIC. LMR-LRT; Lo-Mendell-Rubin likelihood ratio test. BLRT; bootstrap likelihood ratio test.

i The standard errors of the model parameter estimates may not be trustworthy for some parameters due to a non-positive definite first-order derivative product matrix. This may be due to the small group size $(n=1)$ and an indication of model non-identification. 
Table 3. Means (Standard Errors) for Each Feature of the Inventory of Dimensions of Emerging Adulthood as a Function of the Profiles and Wald statistic and Cohen's d Comparing Means and Effect Sizes Across Profiles

\begin{tabular}{|c|c|c|c|c|c|}
\hline Features & $\begin{array}{l}\text { Non-Exploring EA } \\
\text { Profile Mean } \\
(\mathrm{n}=15)\end{array}$ & $\begin{array}{l}\text { EA-Consistent Profile } \\
\text { Mean }(n=138)\end{array}$ & $\chi^{2}$ & p-value & Cohen's di \\
\hline Identity Exploration & $2.288(0.359)$ & $3.531(0.051)$ & $3.809 * * *$ & .000 & 3.191 \\
\hline Experimentation/Possibilities & $3.113(0.233)$ & $3.580(0.042)$ & $2.032 *$ & .042 & 1.050 \\
\hline Negativity/Instability & $2.552(0.322)$ & $3.051(0.050)$ & 1.521 & .128 & 0.756 \\
\hline Other-Focused & $2.438(0.203)$ & $2.386(0.055)$ & -0.243 & .808 & 0.052 \\
\hline Self-Focused & $3.056(0.223)$ & $3.524(0.040)$ & $2.100 *$ & .036 & 1.188 \\
\hline Feeling In-Between & $2.091(0.426)$ & $3.446(0.061)$ & $3.475 * *$ & .001 & 2.562 \\
\hline
\end{tabular}

${ }^{i}$ Note Cohen's d calculated using $\mid$ Mean $\left._{1}-\operatorname{Mean}_{2} \mid / \operatorname{sqrt}\left(\left(\mathrm{n}_{1}-1\right)^{*} \mathrm{sd}_{1}^{2}+\left(\mathrm{n}_{2}-1\right)^{*} \mathrm{sd}_{2}^{2}\right) /\left(\mathrm{n}_{1}+\mathrm{n}_{2}-2\right)\right)$

$* p<.05$

$* * p<.01$

$* * * p<.001$ 
Table 4. Descriptive Statistics for Demographic and Sociodemographic Variables as a Function of Profiles

\begin{tabular}{|c|c|c|c|c|}
\hline \multicolumn{5}{|l|}{ Latent Profile } \\
\hline Variable & $\begin{array}{l}\text { Non-Exploring EA } \\
\text { Profile Mean (SE)/ } \\
\text { Percentage (SE) }\end{array}$ & $\begin{array}{l}\text { EA-Consistent Profile } \\
\text { (SE) }\end{array}$ & $\chi^{2}$ & p-value \\
\hline Age & $21.132(0.601)$ & $21.152(0.162)$ & .001 & .974 \\
\hline Education (years) & $8.551(0.200)$ & $8.299(0.088)$ & 1.280 & .258 \\
\hline Family Income $^{\mathrm{i}}$ & $3.709(0.387)$ & $3.776(0.154)$ & .025 & .875 \\
\hline \multicolumn{5}{|l|}{ Sex } \\
\hline (\% Female) & $59.2 \%(15.3 \%)$ & $66.8 \%(4.3 \%)$ & 1.206 & .547 \\
\hline (\% Male) & $40.8 \%(15.3 \%)$ & $32.5 \%(4.3 \%)$ & & \\
\hline (\% Other) & $0 \%$ & $0.7 \%(0.7)$ & & \\
\hline Romantic Relationship (\%) & $64.8 \%(14.4 \%)$ & $52.0 \%(4.3 \%)$ & .690 & .406 \\
\hline Living with Parents (\%) & $45.2 \%(14.6 \%)$ & $34.1 \%(4.4 \%)$ & .483 & .487 \\
\hline Employed (\%) & $48.8 \%(14.6 \%)$ & $54.9 \%(4.3 \%)$ & .149 & .700 \\
\hline In School (\%) & $55.7 \%(16.7 \%)$ & $70.0 \%(4.5 \%)$ & .593 & .441 \\
\hline Ethnicity & & & .059 & .808 \\
\hline (\% Caucasian) & $46.8 \%(15.1 \%)$ & $42.8 \%(4.3 \%)$ & & \\
\hline (\% Other) & $53.2(15.1 \%)$ & $57.2 \%(4.3 \%)$ & & \\
\hline \multicolumn{5}{|c|}{$\begin{array}{l}\text { "Note. } 1=" \text { Less than } \$ 20,000 " ; 2=" \$ 20,000-\$ 40,000 " ; 3=“ 40,000-\$ 60,000 " ; 4=" \$ 60,000-\$ 80,000 " ; 5=" \$ 80,000-\$ 100,000 " ; \\
6=" \$ 100,000+" . \\
* p<.05 \\
* * p<.01 \\
* * * n<001\end{array}$} \\
\hline
\end{tabular}


Table 5. Summary of Comparisons among Latent Profiles for Psychological Outcomes

\begin{tabular}{lllll}
\hline Latent Profile & & & & \\
\hline Variable & $\begin{array}{l}\text { Non-Exploring EA } \\
\text { Profile Mean (SE) }\end{array}$ & $\begin{array}{l}\text { EA-Consistent Profile } \\
\text { Mean (SE) }\end{array}$ & $\chi^{2}$ & .984 \\
\hline Depression (Baseline) & $18.739(3.511)$ & $18.666(0.847)$ & .000 & .167 \\
Depression (Year1) & $16.034(3.240)$ & $14.644(0.851)$ & 2.491 & .683 \\
Anxiety (Baseline) & $3.673(1.009)$ & $5.425(0.407)$ & .357 & .114 \\
Anxiety (Year 1) & $3.386(1.217)$ & $5.414(0.445)$ & & .125 \\
\hline$* p<.05$ & & & & \\
$* * p<.01$ & & & & \\
$* * * p<.001$ & & & &
\end{tabular}




\section{REFERENCES}

Allem, J., Sussman, S., Soto, D. W., Baezconde-Garbanati, L., \& Unger, J. B. (2016). Role transitions and substance use among hispanic emerging adults: A longitudinal study using coarsened exact matching. Addictive Behaviors, 58, 95-99.

Arnett, J. J. (2000). Emerging adulthood: A theory of development from the late teens through the twenties. American Psychologist, 55(5), 469-480.

Arnett, J. J. (2005). The developmental context of substance use in emerging adulthood. Journal of Drug Issues, 35(2), 235-254.

Asparouhov, T., \& Muthen, B. O. (2013). Auxiliary variables in mixture modeling: A 3-step approach using Mplus (Mplus web notes: No. 15, Version 6).

Bachman, J., O’Malley, P., Schulenberg, J., Johnston, L., Bryant, A., \& Merline, A. (2002). The decline of substance use in young adulthood: Changes in social activities, roles, and beliefs. Mahwah, NJ: Erlbaum.

Baggio, S., Studer, J., Iglesias, K., Daeppen, J., \& Gmel, G. (2017). Emerging adulthood: A time of changes in psychosocial well-being. Evaluation \& the Health Professions, 40(4), 383400.

Bagnardi, V., Zatonski, W., Scotti, L., La Vecchia, C., \& Corrao, G. (2008). Does drinking pattern modify the effect of alcohol on the risk of coronary heart disease? Evidence from a meta-analysis. Journal of Epidemiology \& Community Health, 62(7), 615-619.

Bamberger, P. A., Koopmann, J., Wang, M., Larimer, M., Nahum-Shani, I., Geisner, I., \& Bacharach, S. B. (2018). Does college alcohol consumption impact employment upon graduation? Findings from a prospective study. Journal of Applied Psychology, 103(1), $111-121$. 
Bishop, J. L., Norona, J. C., Roberson, P. N. E., Welsh, D. P., \& McCurry, S. K. (2018). Adult attachment, role balance, and depressive symptoms in emerging adulthood. Journal of Adult Development. Advance online publication.

Boak, A., Hamilton, H. A., Adlaf, E. A., Mann, R. E. (2015). Drug use among Ontario students, 1977-2015: Detailed OSDUHS findings (CAMH Research Document No. 41). Toronto, ON: Centre for Addiction and Mental Health.

Canadian Alcohol and Drug Use Monitoring Survey. (2013). Summary of Results for 2012. Retrieved from https:/www.canada.ca/en/health-canada/services/health-concerns/drugprevention-treatment/drug-alcohol-use-statistics/canadian-alcohol-drug-use-monitoringsurvey-summary-results-2012.html.

Chassin, L., Hussong, A., \& Beltran, I. (2009). Adolescent substance use. In Lerner, R., \& Steinberg, L. (eds.), Handbook of Adolescent Psychology (3rd ed., pp. 723-764). Hoboken, NJ: John Wiley \& Sons.

Chen, P., \& Jacobson, K. C. (2012). Developmental trajectories of substance use from early adolescence to young adulthood: Gender and racial/ethnic differences. Journal of Adolescent Health, 50(2), 154-163.

Clark, S. L., \& Muthén, B. (2009). Relating latent class analysis results to variables not included in the analysis. Available online at: http://www.statmodel.com/download/relatinglca.pdf

Cleveland, M. J., Mallett, K. A., White, H. R., Turrisi, R., \& Favero, S. (2013). Patterns of alcohol use and related consequence in non-college-attending emerging adults. Journal of Studies on Alcohol and Drugs, 74(1), 84-93. 
Clogg, C. C. (1995). Latent class models: Recent developments and prospects for the future. In Arminger G., Clogg C. C., \& Sobel M. E. (Eds.), Handbook of Statistical Modeling for the Social and Behavioral Sciences (pp. 311-352). New York, NY: Plenum.

Collins, R. L., Kashdan, T. B., Koutsky, J. R., Morsheimer, E. T., \& Vetter, C. J. (2008). A selfadministered Timeline Followback to measure variations in underage drinkers' alcohol intake and binge drinking. Addictive Behaviors, 33, 196-200.

Cooper, M. L. (1994). Motivations for Alcohol Use Among Adolescents: Development and Validation of a Four-Factor Model. Psychological Assessment, 6(2), 117-128.

Cooper, M. L., Kuntsche, E., Levitt, A., Barber, L. L., \& Wolf, S. 2016). A motivational perspective on substance use: Review of theory and research on motives for using alcohol, marijuana, and tobacco. In Sher, K. J. (Ed.), Oxford Handbook of Substance Use Disorders (pp. 375-421). New York, NY: Oxford University Press.

Cox, W. M., \& Klinger, E. (1988). A motivational model of alcohol use. Journal of Abnormal Psychology, 97(2), 168-180.

Davis, J. P., Dumas, T. M., Briley, D. A., \& Sussman, S. (2018). A meta-analysis of the association between substance use and emerging adult development using the IDEA scale. American Journal on Addictions, 27(3), 166-176

Erikson, E. H. (1968). Identity: Youth and crisis. Oxford, UK: W. W.Norton.

Fazzino, T. L., Fleming, K., Sher, K. J., Sullivan, D. K., \& Befort, C. (2017). Heavy drinking in young adulthood increases risk of transitioning to obesity. American Journal of Preventive Medicine, 53(2), 169-175.

Galambos, N. L., Barker, E. T., \& Krahn, H. J. (2006). Depression, self-esteem, and anger in emerging adulthood: Seven year trajectories. Developmental Psychology, 42(2), 350-365. 
Gates, J. R., Corbin, W. R., \& Fromme, K. (2016). Emerging adult identity development, alcohol use, and alcohol-related problems during the transition out of college. Psychology of Addictive Behaviors, 30(3), 345-355.

Gmel, G., Bissery, A., Gammeter, R., Givel, J. C., Calmes, J. M., Yersin, B., \& Daeppen, J. B. (2006). Alcohol-attributable injuries in admissions to a Swiss Emergency Room - An analysis of the link between volume of drinking, drinking patterns, and preattendance drinking. Alcoholism: Clinical and Experimental Research, 30(3), 501-509.

Gmel, G., Kuntsche, E., \& Rehm, J. (2011). Risky single-occasion drinking: Bingeing is not bingeing. Addiction, 106(6), 1037-1045.

Goldstein, A. L., Haller, S., Mackinnon, S. P., \& Stewart, S. H. (2018). Attachment anxiety and avoidance, emotion dysregulation, interpersonal difficulties and alcohol problems in emerging adulthood. Addiction Research \& Theory. Advance online publication.

Goodman, I., Henderson, J., Peterson-Badali, M., \& Goldstein, A. L. (2015). The relationship between psychosocial features of emerging adulthood and substance use change motivation in youth. Journal of Substance Abuse Treatment, 52, 58-66.

Hagenaars J. A. (1993). Loglinear Models with Latent Variables. London: Sage.

Hagger-Johnson, G., Taibjee, R., Semlyen, J., Fitchie, I., Fish, J., Meads, C., \& Varney, J. (2013). Sexual orientation identity in relation to smoking history and alcohol use at age 18/19: cross-sectional associations from the Longitudinal Study of Young People in England (LSYPE). British Medical Journal Open, 3(8), e002810

Jackson, K. M., \& Sartor, C. E. (2016). The natural course of substance use and dependence. In K. J. Sher (Ed.), The Oxford handbook of substance use and substance use disorders (vol. 1, pp. 67-131). New York, NY: Oxford University Press. 
Jochman, K., \& Fromme, K. (2010). Maturing out of substance use: The other side of etiology. In L. M. Scheier (Ed.), Handbook of drug use etiology: Theory, methods, and empirical findings (pp. 565-578). Washington, DC: American Psychological Association.

Johnston, L. D., O'Malley, P. M., Bachman, J. G., Schulenberg, J. E., \& Miech, R. A. (2016). Monitoring the Future national survey results on drug use, 1975-2015: Volume II, college students and adults ages 19-55. Ann Arbor: Institute for Social Research, The University of Michigan. Available at http://monitoringthefuture.org/pubs.html\#monographs

Johnston, L. D., Miech, R. A., O'Malley, P. M., Bachman, J. G., Schulenberg, J. E., \& Patrick, M. E. (2018). Monitoring the Future national survey results on drug use, 1975-2017: Overview, key findings on adolescent drug use. Ann Arbor: Institute for Social Research, The University of Michigan.

Kahler, C. W., Strong, D. R., \& Read, J. P. (2005). Toward efficient and comprehensive measurement of the alcohol problems continuum in college students: The brief young adult alcohol consequences questionnaire. Alcoholism: Clinical and Experimental Research, 29(7), 1180-1189.

Kahler, C. W., Hustad, J., Barnett, N. P., Strong, D. R., \& Borsari, B. (2008). Validation of the 30-day version of the brief young adult alcohol consequences questionnaire for use in longitudinal studies. Journal of Studies on Alcohol and Drugs, 69(4), 611-615.

Kamata, A., Kara, Y., Patarapichayatham, C., \& Lan, P. (2018). Evaluation of analysis approaches for latent class analysis with auxiliary linear growth model. Frontiers in Psychology. Advance online publication. 
Kendler, K. S., Lönn, S. L., Salvatore, J., Sundquist, J., \& Sundquist, K. (2016). Effect of marriage on risk for onset of alcohol use disorder: A longitudinal and co-relative analysis in a Swedish national sample. American Journal of Psychiatry, 173(9), 911-918.

Kessler, R. C., \& Wang, P. S. (2008). The Descriptive Epidemiology of Commonly Occurring Mental Disorders in the United States. Annual Review of Public Health, 29(1), 115-129.

Kuntsche, E, Knibbe, R., Gmel, G, Engels, R (2006). Replication and Validation of the Drinking Motive Questionnaire Revised (DMQ-R, Cooper, 1994) among Adolescents in Switzerland. European Addiction Research, 12(3), 161-168.

Kuntsche, E., Knibbe, R., Engels, R., \& Gmel, G. (2010). Being drunk to have fun or to forget problems?: Identifying enhancement and coping drinkers among risky drinking adolescents. European Journal of Psychological Assessment, 26(1), 46-54.

Kuntsche, E., Gabhainn, S. N., Roberts, C., Windlin, B., Vieno, A., Bendtsen, P., Hublet, A., Tynjala, J., Valimaa, R., Dankulincova, Z., Aasvee, K., Demetrovics, Z., Farkas, J., van der Sluijs, W., de Matos, M.G., Mazur, J., Wicki, M. (2014). Drinking motives and links to alcohol use in 13 European countries. Journal of Studies on Alcohol and Drugs, 75(3), $428-437$.

Kuntsche, E., Kuntsche, S., Thrul, J., \& Gmel, G. (2017). Binge drinking: Health impact, prevalence, correlates and interventions. Psychology \& Health, 32(8), 976-1017.

Lau-Barraco, C., Linden-Carmichael, A. N., Hequembourg, A., \& Pribesh, S. (2017). Motivations and consequences of alcohol use among heavy drinking nonstudent emerging adults. Journal of Adolescent Research, 32(6), 667-695.

Lanctot, J., \& Poulin, F. (2018). Emerging adulthood features and adjustment: A person-centered approach. Emerging Adulthood, 6(2), 91-103. 
Lane, J. (2014). Counseling emerging adults in transition: Practical applications of attachment and social support research. The Professional Counselor, 5 (1), 30-42.

Lisha, N., Grana, R., Sun, P., Rohrbach, L., Spruijt-Metz, D., Reifman, A., \& Sussman, S. (2014). Evaluation of the psychometric properties of the Revised Inventory of the Dimensions of Emerging Adulthood (IDEA-R) in a sample of continuation high school students. Evaluation \& the Health Professions, 37(2), 156-177.

Lisha, N. E., Leventhal, A. M., Rohrbach, L., Spruijt-Metz, D., Sun, P., \& Sussman, S. (2015). The relationship of emerging adulthood trajectories to drug use and other correlates.. Salud Y Drogas, 15(2), 91-102.

Loken, E. (2004). Using latent class analysis to model temperament types. Multivariate Behavioral Research, 39(4), 625-652.

Löwe, B., Decker, O., Müller, S., Brähler, E., Schellberg, D., Herzog, W., \& Herzberg, P. Y. (2008). Validation and standardization of the generalized anxiety disorder screener (GAD7) in the general population. Medical Care, 46(3), 266-274.

Marcia, J. E. (1966). Development and validation of ego-identity status. Journal of Personality and Social Psychology, 3(5), 551-558.

Matusiewicz, A. K., Ilgen, M. A., \& Bohnert, K. M. (2016). Changes in alcohol use following the transition to motherhood: Findings from the national epidemiologic survey on alcohol and related conditions. Drug and Alcohol Dependence, 168, 204-210.

McLachlan, G.J., Peel, D., 2000. Finite Mixture Models. Wiley, New York.

Miech, R. A., Johnston, L. D., O'Malley, P. M., Bachman, J. G., \& Schulenberg, J. E., \& Patrick, M. E. (2017). Monitoring the Future national survey results on drug use, 1975-2016: 
Volume I, secondary school students. Ann Arbor: Institute for Social Research, The University of Michigan

Mushquash, A. R., Stewart, S. H., Sherry, S. B., Sherry, D. L., Mushquash, C. J., \& MacKinnon, A. L. (2013). Depressive symptoms are a vulnerability factor for heavy episodic drinking: A short-term, four-wave longitudinal study of undergraduate women. Addictive Behaviors, 38(5), 2180-2186.

Muthen, B.O. (2004). Growth mixture modeling and related techniques for longitudinal data. In D. Kaplan (Ed.), Handbook of quantitative methodology for the social sciences (pp. 345368). Newbury Park, CA: Sage.

Muthen, L. K., \& Muthen, B. O. (1998-2017). Mplus user's guide. Los Angeles, CA: Author Nylund, K. L., Asparouhov, T., \& Muthen, B. O. (2007). Deciding on the number of classes in latent class analysis and growth mixture modeling: A Monte Carlo simulation study. Structural Equation Modeling, 14, 535-569.

Patrick, M. E., \& Schulenberg, J. E. (2011). How trajectories of reasons for alcohol use relate to trajectories of binge drinking: National panel data spanning late adolescence to early adulthood. Developmental Psychology, 47(2), 311-317.

Patrick, M. E., Schulenberg, J. E., O'Malley, P. M., Maggs, J. L., Kloska, D. D., Johnston, L. D., \& Bachman, J. G. (2011). Age-related changes in reasons for using alcohol and marijuana from ages 18 to 30 in a national sample. Psychology of Addictive Behaviors, 25(2), 330339.

Patrick, M. E., Terry-McElrath, Y. M., Kloska, D. D., \& Schulenberg, J. E. (2016). Highintensity drinking among young adults in the United States: Prevalence, frequency, and developmental change. Alcoholism: Clinical and Experimental Research, 40, 1905-1912. 
Phinney, J. S., \& Kohatsu, E. L. (1997). Ethnic and racial identity development and mental health. In J. Schulenberg, J. L. Maggs, \& K. Hurrelmann (Eds.), Health risks and developmental transitions during adolescence (pp. 420-443). New York, NY, US: Cambridge University Press.

Quinn, P. D., \& Harden, K. P. (2013). Differential changes in impulsivity and sensation seeking and the escalation of substance use from adolescence to early adulthood. Development and Psychopathology, 25(1), 223-239.

Read, J. P., Kahler, C. W., Strong, D. R., \& Colder, C. R. (2006). Development and preliminary validation of the Young Adult Alcohol Consequences Questionnaire. Journal of Studies on Alcohol, 67 (1), 169-177.

Radloff, L.S. (1977). The CES-D scale: A self report depression scale for research in the general population. Applied Psychological Measurement, 1(3), 385-401.

Reich, R. R., Cummings, J. R., Greenbaum, P. E., Moltisanti, A. J., \& Goldman, M. S. (2015). The temporal "pulse" of drinking: Tracking 5 years of binge drinking in emerging adults. Journal of Abnormal Psychology, 124(3), 635-647.

Reifman, A., Arnett, J. J., \& Colwell, M. J. (2007). Emerging adulthood: Theory, assessment and application. Journal of Youth Development, 2(1), 37-48.

Schulenberg, J. E., Johnston, L. D., O'Malley, P. M., Bachman, J. G., Miech, R. A., \& Patrick, M. E. (2017). Monitoring the Future national survey results on drug use, 1975-2016:

Volume II, college students and adults ages 19-55. Ann Arbor: Institute for Social Research, The University of Michigan. Available at http://monitoringthefuture.org/pubs.html\#monographs 
Schwartz, S. J. (2016). Turning point for a turning point: Advancing emerging adulthood theory and research. Emerging Adulthood, 4(5), 307-317.

Sher, K. J., \& Gotham, H. (1999). Pathological alcohol involvement: A developmental disorder of young adulthood. Development and Psychopathology, 11(4), 933-956.

Simons-Morton, B., Haynie, D., Liu, D., Chaurasia, A., Li, K., \& Hingson, R. (2016). The effect of residence, school status, work status, and social influence on the prevalence of alcohol use among emerging adults. Journal of Studies on Alcohol and Drugs, 77(1), 121-132.

Smith, D. C., Bahar, O. S., Cleeland, L. R., \& Davis, J. P. (2014). Self-perceived emerging adult status and substance use. Psychology of Addictive Behaviors, 28(3), 935-941.

Sobell, L. C., \& Sobell, M. B. (1992). Timeline Follow-Back. In Measuring Alcohol Consumption (pp. 41-72). Totowa, NJ: Humana Press.

Spitzer, R. L., Kroenke, K., Williams, J. B. W., \& Löwe, B. (2006). A brief measure for assessing generalized anxiety disorder: The GAD-7. Archives of Internal Medicine, 166(10), 1092-1097.

Sussman, S., \& Arnett, J. J. (2014). Emerging adulthood: Developmental period facilitative of the addictions. Evaluation and the Health Professions, 37(2), 147-155.

Tagliabue, S., Crocetti, E., \& Lanz, M. (2016). Emerging adulthood features and criteria for adulthood: Variable- and person-centered approaches. Journal of Youth Studies, 19(3), 374-388.

Tarter, R., \& Vanyukov, M. (1994). Alcoholism: A developmental disorder. Journal of Consulting and Clinical Psychology, 62(6), 1096-2007. 
Taylor, Z. E., Doane, L. D., \& Eisenberg, N. (2014). Transitioning from high school to college: Relations of social support, ego-resiliency, and maladjustment during emerging adulthood. Emerging Adulthood, 2(2), 105-115.

Thompson, K., Roemer, A., \& Leadbeater, B. (2015). Impulsive personality, parental monitoring, and alcohol outcomes from adolescence through young adulthood. Journal of Adolescent Health, 57(3), 320-326.

van Damme, J., Maes, L., Clays, E., Rosiers, J. F. M. T., Van Hal, G., \& Hublet, A. (2013). Social motives for drinking in students should not be neglected in efforts to decrease problematic drinking. Health Education Research, 28(4), 640-650.

van Damme, J., Maes, L., Kuntsche, E., Crutzen, R., De Clercq, B., Van Lippevelde, W., \& Hublet, A. (2015). The influence of parental drinking on offspring's drinking motives and drinking: A mediation analysis on 9 year follow-up data. Drug and Alcohol Dependence, 149, 63-70.

van der Zwaluw, C., Kuntsche, E., \& Engels, R. C. (2011). Risky alcohol use in adolescence: The role of genetics (DRD2, SLC6A4) and coping motives. Alcoholism: Clinical and Experimental Research, 35(4), 756-764.

Wang, M., \& Hanges, P. J. (2011). Latent class procedures: Applications to organizational research. Organizational Research Methods, 14(1), 24-31.

Wang, J., \& Wang, X. (2012). Mixture modeling. In Balding, D. J. (Ed.), Structural equation modeling: Applications using Mplus (pp. 289-390). Chichester, UK: Wiley.

White, H. R., \& Jackson, K. (2004). Social and psychological influences on emerging adult drinking behavior. Alcohol Research \& Health, 28(4), 182-190. 
Wicki, M., Kuntsche, E., Eichenberger, Y., Aasvee, K., Bendtsen, P., Dankulincová Veselská, Z., Demetrovics, Z., Dzielska, Z., Farkas, J., de Matos, M.G., Roberts, C., Tynjala, J., Valimaa, R., Vieno, A. (2017). Different drinking motives, different adverse consequences? Evidence among adolescents from 10 European countries. Drug and Alcohol Review, 36(6), 731-741 